\title{
Nursing Science in the Global Community
}

\author{
Shaké Ketefian, Richard W. Redman
}

\begin{abstract}
Knowledge development and research are generally embedded in cultural values and perspectives. This article examines the development of knowledge in nursing in a global context and addresses the degree to which Western values and the social environment in the United States shape nursing theory development. Three perspectives illustrate the influence of US values and contextual factors. Questions are raised about the relevance of knowledge to other cultural or national contexts. Recommendations are made for nursing inquiry that makes knowledge more applicable to the global community.
\end{abstract}

image: Journal of Nursing Scholarship, 1997; 29(1), 11-15. C1997, Sigma Theta Tau International.

[Keywords: knowledge development; international nursing]

F or many years, nurses from other countries have been enrolled in U.S. graduate programs. Colling and Liu (1995) report a $10 \%$ increase in international students attending U.S. graduate programs in nursing in the past decade. In their survey of international students, these authors identified 239 students from 49 countries. In many parts of the world, US nursing appears to be highly regarded.

As the diversity and ethnic mix of the U.S. population has increased, global awareness has also increased. In the past decade, many institutions and nurses have become involved in international activities such as consultation, collaborative research, and exchange visitor arrangements.

Yet, despite the increase in international activities, the nature of nursing theory, research, education, and practice has not changed appreciably to be globally relevant. The degree to which parochialism may have played a role in explaining the slow pace of change in this regard has not been fully examined.

Boyacigiller and Adler (1991) examined the degree to which Western parochialism and ethnocentrism are embedded in the concepts of organizational theory. These authors reviewed the research literature in management science from three perspectives: (a) the influence of post World War II America and its environment on organizational theory development; (b) the volume of international articles published in American management journals; and (c) the degree to which American beliefs and values have shaped organizational theory development. Their assessment, overall, was that organizational theories are parochial and many do not acknowledge awareness of non-U.S. contexts, models, or values. Many Americans have shaped theories central to organizational and human behavior with the assumption that these beliefs have universal applicability. Free will (versus determinism) and individualism (versus collectivism) are just two examples of how Western values have shaped research and theory in organizational science.
The authors call for the development of organizational sciences in which universal, intercultural theories are clearly explicit.

Following the approach taken by Boyacigiller and Adler (1991), we describe three perspectives in our examination: (a) contextual-the influence of the U.S. social environment on nursing theory development; (b) quantitative-the rapid expansion of U.S. doctoral programs in nursing, the shaping of nursing journals by U.S. nurse scientists, and the degree of international scientific representation in these journals; and (c) qualitative- the degree to which U.S. values have shaped nursing theory development. The status of multicultural knowledge development in the United States is then presented followed by selected recommendations. Given the magnitude of the topic, no attempt is made to be comprehensive. Rather, the ideas presented represent select perspectives and observations of the authors who are educators in the United States, but who have had extensive international experience. The views presented here are intended to serve as catalysts for further discussion.

\section{Perspectives}

\section{Contexual Perspective}

The influence of social forces on American nursing can be examined from several perspectives. These include (a) social

\footnotetext{
Shaké Ketefian, RN, EdD, FAAN, Rho, is Professor and Director of Doctoral and Postdoctoral Studies; Richard W. Redman, RN, PhD, is Associate Professor and Director of the Division of Nursing and Health Care Systems. Both are at the School of Nursing, University of Michigan. The authors wish to note that this essay was prepared as background to the deliberations of the 1995 Annual Forum on Doctoral Education, held in Dearborn, Michigan, June 1995. Correspondence to Dr. Ketefian, School of Nursing, University of Michigan, 400 North Ingalls, Ann Arbor, Ml 48109.

Accepted for publication: February 12, 1996.
} 
trends and values and how they shape nursing knowledge development, (b) the influence of technology and reimbursement systems on nomenclature in nursing, and (c) the development of nursing education and research infrastructures as social phenomena. Each is described briefly to illustrate the contextual influences.

Many recent U.S. social movements have had considerable effect on nursing theory. One example is the emphasis on health promotion and risk reduction. The social emphasis on behavior related to diet, exercise, and other types of health-promoting behaviors have influenced the shaping of public policy as well as the education of health professionals. To a considerable degree, they have also shaped the direction of nursing science and research. Another example is the way in which the emergence of the women's movement has shaped the thinking of a whole generation of women and has led to the development of new public policies in education, employment, health, and other domains. Recognition that women's health problems should be given priority has led to research by health professionals, including nurses, resulting in a body of scientific knowledge in this domain.

The Nursing Interventions Classification (NIC) work at Iowa (McCloskey \& Bulechek, 1994) is another example of a social force influencing nursing knowledge development. NIC has been developed as a comprehensive classification of treatments that nurses perform in an attempt to create a standardized language of both nurse- and physician-initiated nursing interventions. Interest in developing this taxonomy can be traced in part to the need for nurses to develop a universal language. Catalytic social forces such as the rapid technologic development of literature data bases, clinical information systems in practice settings, and the need for taxonomies that are compatible with reimbursement systems have resulted in the need for standardized nursing nomenclature. This development has profound implications for nursing practice and knowledge development internationally. The degree to which U.S. nursing interventions are shaping the rapid development of "universal" taxonomies and languages that reflect nursing practice throughout the world is a pressing question. In addition, there is considerable interest in using taxonomies such as NIC to redefine nursing knowledge inductively. Again, the degree to which U.S. nursing interventions and practices reflect nursing practice in other countries is a question of critical importance internationally.

Social values and contextual influence also relate to the quality of nursing care. Definitions of nursing care quality vary, ranging from using the proper amount of resources to accomplish nursing goals to meeting patients' requirements. Assessing the quality of nursing care, whether focused on the appropriateness of a given intervention to a patient's needs or the selection of alternatives as a function of resources available illustrates how context-dependent quality can be. The expectations of a client, the socially defined role of the nurse, and the technology available can vary considerably. Furthermore, the importance of each of these variables in the quality equation can vary, depending on the context, and in turn drive the research questions and methodologies. Thus, the manner in which the pressing questions of the discipline are framed are very likely to reflect the values, philosophy, and practices of the culture and society in which they are asked.
Explorations of theory in nursing began in the 1960s. Since then, in an effort to define what is distinctive about nursing science and theory, nurse scholars and theorists have widely debated their ideas. Many of these ideas have been characterized as metatheories or conceptual frameworks. In the past decade, the nursing literature has reflected a shift in thinking. Now many investigators favor working with propositions and theories characterized as middle-range theories rather than with conceptual frameworks because middle-range theories provide the basis for generating testable hypotheses related to particular nursing phenomena and to particular patient populations.

Expansion of doctoral programs along with the magnitude and refinement of nursing research over the past several decades has been impressive. Thus, it can be argued that such advances in U.S. nursing have rightfully placed it in an enviable position vis-á-vis international peers.

The scope and orientation of much of nursing research is American without global characteristics. Frequently, research findings are presented and received by international colleagues as though the work is applicable to other national and cultural contexts. In addressing such issues, Zwanger (1987) states that American nurses are recognized as leaders in doctoral education in the world and that,

They are ... the oracles of the international academic nursing community. As a consequence, in many instances, their ambiguous tendencies, unclarified ideas, and conceptions are accepted as bona fide facts (pp. 33-34).

Zwanger draws on the Israeli experience in stating that some of those who complete their degree in the United States wish to transplant American ideas to their native land. She then describes the inappropriateness of doing so, which in some cases results in failure to function effectively in one's home settings. She makes a case for U.S. doctoral faculty to "pay attention to global content and international nursing issues," emphasize comparative studies, and assist international students to gear their doctoral research to problems in their own countries.

\section{Quantitative Perspective}

The International Council of Nurses now represents 110 national associations as members, with a total of 1 million nurses (Splane \& Splane, 1994). Of 110 schools worldwide offering doctoral degrees in nursing, 62 are in the United States and 48 in all other countries combined. Moreover, according to anecdotal data, an indeterminate number of non-U.S. educational programs are programs where nurses have the opportunity to obtain doctoral degrees in fields other than nursing.

A limited number of international exchanges of students and faculty has occurred over the years (Fenton, 1994), although exchange has gained momentum recently. Yet, such opportunities are not made available to students by many institutions; further, international exchanges typically occur during undergraduate study rather than graduate study. At the doctoral level, during the $1970 \mathrm{~s}$, many institutions either abandoned a second language requirement altogether or began accepting a computer language in its stead. A recent American Academy of Nursing publication (1995) identifies five graduate programs in nursing in the United States with a cross-cultural focus, some of which include 
international nursing. Thus, in most cases, doctoral students' exposure to the world beyond the United States might come when they have the opportunity to study with international students as peers.

Examination of the growth in journal publication and in doctoral education gives readers another perspective on the growth in nursing knowledge and science. The major journal for reporting research in nursing, Nursing Research, was established in 1952 by the American Journal of Nursing Company; later it was followed by the publication of Research in Nursing and Health in 1977, and Advances in Nursing Science in 1978. Since that time, many journals have been established that report research in nursing, nursing theory, and nursing practice. As specialty organizations grew, so did journals concerned with the practice and research of their clinical area of practice. In the early days of Nursing Research, it was not uncommon to see papers authored by social scientists, reporting on studies concerned with nurses rather than with nursing.

Ketefian and Redman (1994) reported that the first doctoral programs in nursing were established in 1933 (Teachers College, Columbia University), and 1934 (New York University), both offering the Doctor of Education degree. In the next 25 years, only two more programs were established. Growth in doctoral programs since then has been exponential. Of the 62 institutions in the United States offering doctoral degrees in nursing $75 \%$ offer the $\mathrm{PhD}$, the remainder offer a DNS, DNSc, or EdD. As to the nature of these programs, Grace (1978) and Murphy (1981) have described the development of doctoral programs in three phases: Phase I (inception to 1959) is characterized by focusing on education for nurses for functional roles; Phase II (1960-69) is characterized by a focus on education for nurses in a second discipline, referred to as nurse scientist training; Phase III (1970 to the present) is characterized by a focus on education in and of nursing .

A review of the content of U.S. journals suggests that many report on international issues, some have articles co-authored by nurses from overseas, and others have a regular international column. But the effect of these developments, while significant, is not major. Many libraries now subscribe to international journals; yet class assignments do not often include readings from these journals. A few journals now have international representatives on their review boards.

\section{Qualitative Perspective}

The Code for Nurses (ANA, 1985) represents embodiment of the values of American Nursing. The preamble reads, in part:

When making clinical judgments, nurses base their decisions on consideration of consequences and of universal moral principles, both of which prescribe and justify nursing actions. The most fundamental of these principles is respect for persons. Other principles stemming from this basic principle are autonomy (self-determination), beneficence (doing good), nonmaleficence (avoiding harm), veracity (truth-telling), confidentiality (respecting privileged information), fidelity (keeping promises), and justice (treating people fairly)" (p. i).

The values in the code, and others emanating from them, find expression in nursing theories and conceptual frameworks developed by U.S. scholars. Indeed, they permeate the nursing literature. These values are at times explicit and at other times implicit.

Why are value assumptions important? Values have important effects on people, communities, and societies; the primary concern of nursing is people-individually or in the aggregate. An understanding of behavior and the values that underlie behavior, becomes a critical starting point for designing and implementing nursing interventions. Value assumptions underlying U.S. nursing are profoundly influenced by American culture, social mores, and the biases of the people who produce this literature. Yet, a reading of U.S. literature suggests that the ideas therein are claimed to be either acultural or universal.

Most nursing theories and nursing research are developed and implemented in the United States, and therefore, can be said to be influenced by the social and cultural context of this country. In the next section, we offer specific examples of the influence of culturally-specific values and assumptions-and present comparisons or contrasts gleaned from the literature.

Graduate and higher education in nursing. In the United States, it is assumed that academic study is "good" and necessary for nursing education and that higher education (at college and university level) is even better. However, in many countries these are not assumptions; the terms often have different meanings.

Hockey (1987) draws on her knowledge and experience in European countries, and states that in some countries "higher education" refers to academic study beyond that required for qualification for practice. In addition, she explains that typically with higher education come leadership positions, even though some nurses do not wish to assume such positions. Thus she poses the dilemma in ethical terms: Is "higher education" necessary for nursing? In another poignant example from the Austrian experience, she reveals that nurse training begins at age 15 , and notes that "nursing autonomy assumes a different meaning" under these circumstances (p. 77).

Another author from the same conference describes the experience of Norway and its dilemmas which highlight value conflicts and value differences of a significant magnitude for that country. The main dilemma posed by Haugen Bunch (1987) is whether Norwegian nurses should study in the United States or in Norway. Each choice is described as having significant consequences for Norwegian nursing. She describes the choices as (a) studying social and natural sciences, (b) developing nursing science, or (c) blending the two. At the University of Bergen (Norway), where an Institute of Caring Sciences was established in 1979, many believe that caring is not subject to scientific inquiry, that nursing cannot be both holistic and scientific, that science may compromise the nursing discipline, that nursing can use relevant scientific principles from other disciplines, and that there is no need for a separate nursing science. Thus, if nurses study in Norway, with its tutorial educational model, their role models will not be nurses and they will learn the traditions of other disciplines rather than of nursing. If, on the other hand, they study in the United States, they will be socialized in nursing's scientific tradition and will have nurse role models. Haugen Bunch warns that for those educated in the U.S. there will be the danger of bringing back to Norway "undigested 
American knowledge that is presented as 'Norwegian truisms'forgetting the need for value clarification so that the knowledge will fit Norwegian culture and traditions" (p. 103). Throughout her presentation she emphasizes the importance of adapting and testing theories and concepts before, "being applied and integrated to the Norwegian culture" (p. 103).

Nursing science and Japan. According to a Japanese nurse who did graduate work in the United States, Japanese nurses have imported nursing knowledge and literature since the end of the 19th century. The works of many American authors and theorists have been translated into Japanese by exchange nurses and by those who came to the U.S. for master's and doctoral degrees (Minami, 1987). Minami claims that many of these nurses "were not aware of the differences between the Japanese and American cultures or social context" (p. 66), and claimed that nursing was universal. She describes fundamental differences in the cultural milieu of the two countries that make concepts developed in one country inapplicable or irrelevant in the other. She also describes dilemmas faced by American-educated Japanese nurses in functioning in their home settings. Communication differences, for example, exist in eight areas: physical proximity; self disclosure; trust in words; boundary in human relationships; commitment and contract; dependency and independence; autonomy and independence; and confrontation (p. 70). She says that Americans communicate with language while Japanese communicate with empathy; and she provides examples. These differences are characterized by Boyacigiller and Adler (1991) as high-context or low-context cultures. The external environment, the situation, and non-verbal behavior determine communication in high-context cultures like the Japanese, and subtlety, facial expression, relationship, and timing are valued. In low-context cultures like the USA, meaning comes from the spoken word and legal contracts are valued.

\section{Multicultural Knowledge \\ Development in the United States}

Rapid change in the demographic composition of the U.S. population has occurred within the past several decades. Some demographers estimate that by the twenty-first century, one-third to one-half of the population will be other than Euro-Caucasian. Thus a reversal is anticipated whereby groups that were minorities will collectively become the majority. The importance of a change of such magnitude is immense. An appreciation for diversity and for the varying needs of people who are different-with regard to any number of characteristics-is needed. Nowhere is this appreciation more compelling than in health care and nursing.

A small group of nurse investigators has been developing research and theory that is culturally sensitive. In a recent American Academy of Nursing monograph (AAN, 1995), a group of authors define culturally-competent care as that which "takes into account issues related to diversity, marginalization, and vulnerability due to culture, race, gender, and sexual orientation" (p. 4). In their assessment of the state of knowledge development in this area, the authors identify the dearth of principles to guide selection of culturally sensitive research questions and selection of culturally appropriate methodologies. Many nursing programs do not offer content relevant to this area and fewer still require doctoral students to enroll in seminars about cross-cultural nursing.

The authors of the AAN monograph (1995) identify two metatheories and studies based on them that have shown promise of generating knowledge that is culturally sensitive. One theory is Leininger's (1985), wherein she posits that care, as the essence of nursing, is universal across cultures, although its forms and expressions may vary. The authors cite a number of nursing studies in which Leininger's theory helped researchers generate knowledge related to cultural care. The other metatheory cited is the "self-care deficit theory" (Orem, 1991). This theory enables study of self-care practices used by diverse social groups. Its relevance for populations in a number of European countriesas well as Mexico and Thailand-is being studied by a network of collaborators (AAN, 1995).

In addition to the two metatheories, others are being developed that are referred to as "situation specific theories" (AAN, 1995). Examples are studies of Middle Eastern immigrants (Lipson, Reizian, \& Meleis, 1987; Meleis, 1981; Meleis \& Jonsen, 1983), patterns of health-seeking behaviors among Arab children (May, 1985), and post-partum transition among Arab women (El Sayed, 1986). The authors contend that, collectively, such studies can be synthesized to provide conceptualizations of patterns of responses to health-illness transitions, thus enabling development of a situation-specific theory in a particular population (AAN, 1995, p. 10).

Methodological concerns in the conduct of research with ethnically and racially diverse groups have received increasing attention as well. The US Department of Health and Human Services (1990) has recently stipulated that ethnically and racially different groups be included as research subjects. Porter and Villarruel (1993) provide a cogent analysis of research issues and propose a set of guidelines to be considered for the design of research. Consideration of appropriate sensitivity is reflected in conceptualizing and conducting research, including each step of the research process and investigator activities. It is implied that unless these design considerations are present and deliberatively addressed, the relevance and applicability of the outcome of the research to diverse populations would be questionable.

Other knowledge development strategies. Over the years, nurses in many countries have identified their inability to describe nursing practice, client populations, or geographic areas as a serious constraint (Clark, 1994). To meet this need, and to contribute to knowledge development for nursing, various classification systems have been developed. The Nursing Minimum Data Set was developed by Werley in the late 1960 s (Werley \& Lang, 1988) and in turn spurred other developments.

In the early 1980s, a classification of nursing diagnoses was proposed by the North American Nursing Diagnosis Association, where the phenomenon of concern is patient status (McLane, 1987). More recently, the Nursing Interventions Classification (NIC) project was developed. The use of nursing diagnoses and NIC are becoming widespread in the United States and internationally. Such standardization has many advantages: it helps expand nursing's knowledge base, provides a common language to communicate the functions of nursing, provides shared understanding of nursing practice across national and 
cultural boundaries, and highlights the distinctive contribution nursing makes toward solving health problems. The International Council of Nurses currently has a project in progress with these goals in mind (Clark, 1994). Although we do not know how the different knowledge development strategies will evolve, significant developments are providing the basis on which to build continuing work by nurse scholars in doctoral programs around the world.

\section{Next Steps}

Some authors discuss the urgent need to develop nursing knowledge relevant to the health of the global community (Meleis, 1993). A Western perspective generally pervades organizing concepts and frameworks in nursing and thus is a dominating influence in knowledge development and research. Meleis expressed concern that U.S. nursing doctoral programs may be producing nurse scientists who do not challenge Western perspectives, particularly in terms of definitions and assumptions related to nursing phenomena.

In 1997 we are at a critical juncture for American nursing science. Given the global society in which we live, nursing science now faces the challenge of moving to its next phase of development, which we call "becoming globally relevant." This movement entails a variety of activities and changes in the way we do science, a responsibility that should be shared by scientists in the U.S. and internationally. We need to test nursing models, propositions, and hypotheses in several countries; include relevant content in educational programs; provide opportunities for doctoral students to develop nursing research internships abroad; involve international scholars in editorial review boards; increase the representation of international authors in U.S. journals and vice versa; encourage international students to focus their dissertations on topics pertinent to their countries; integrate collaborative international research in the ongoing work of scientists in leading nursing institutions throughout the world, and expand the criteria for promotion and tenure to include such activity.

We hope the questions raised in this essay will be viewed as opportunities by the global nursing community. If future discussions result in recognition of the challenges facing nursing knowledge development and doctoral education throughout the world, then our purpose will have been served. 2
Boyacigiller, N.A., \& Adler, N.J. (1991). The parochial dinosaur: Organizational science in a global context. Academy of Management Science, 16(2), 262290.

Clark, J. (1994). The international classification of nursing. In J. McCloskey, \& H.K. Grace (Eds.). Current issues in nursing (4th ed.) (143-147). St. Louis, MO: Mosby-Year Book.

Colling, J.C., \& Liu, Y.C. (1995). International nurses' experiences seeking graduate education in the United States. Journal of Nursing Education, 34(4), 162-166.

El Sayed, Y.A. (1986). The successive-unsettled transitions of migration and their impact on postpartum concerns of Arab immigrant women. Unpublished doctoral dissertation, University of California, San Francisco.

Fenton, M.V. (1994). Development of models of international exchange to upgrade nursing education. In J. McCloskey, \& H.K. Grace (Eds.). Current issues in nursing (4th ed.) 202-206. St. Louis, MO: Mosby-Year Book.

Grace, H. (1978). The development of doctoral education in nursing: An historical perspective. Journal of Nursing Education, 17(4), 17-27.

Haugen Bunch, E. (1987). International perspectives and implications for doctoral education in nursing: Norwegian perspective. In International perspectives and implications for doctoral education in nursing (97-105). Portland, OR: Oregon Health Sciences University School of Nursing.

Hockey, L. (1987). Ethical issues in higher education in nursing. In International perspectives and implications for doctoral education in nursing (75-85). Portland, OR: Oregon Health Sciences University School of Nursing.

Ketefian, S., \& Redman, R.W. (1994). The changing face of graduate education. In J. McCloskey, \& H.K. Grace (Eds.). Current issues in nursing (4th ed.) (188-195). St. Louis, MO: Mosby-Year Book.

Leininger, M.M. (1985). Ethnography and ethnonursing: Models and modes of qualitative data analysis. In M.M. Leininger (Ed.). Qualitative methods in nursing. New York: Grune \& Stratton.

Lipson, J.G., Reizian, A., \& Meleis, A.I. (1987). Arab-American patients: A medical record review. Social Science and Medicine, 24(2), 101-107.

May, K.M. (1985). Arab-American immigrant parents' social networks and health care of children. Unpublished doctoral dissertation, University of California, San Francisco.

McCloskey, J.C., \& Bulechek, G.M. (1994). Standardizing the language for nursing treatments: An overview of the issues. Nursing Outlook, 42(2), 4563.

McLane, A.M. (1987). Classification of nursing diagnoses: Proceedings of the seventh conference. St. Louis, MO: Mosby-Year Book.

Meleis, A.I. (1981). The Arab-American in the Western health care system. American Journal of Nursing, 6, 1180-1183.

Meleis, A.I., \& Jonsen, A. (1983). Ethical crises and cultural differences. The Western Journal of Medicine, 138(6), 889-893.

Meleis, A.I. (1993). A passion for substance revisited: Global transitions and international commitments. In Proceedings of the 1993 Annual forum on doctoral nursing education (5-22). St. Paul, MN, University of Minnesota School of Nursing.

Minami, H. (1987). Reflections of the cultural and social milieu on the development of nursing science in Japan. In International perspectives and implications for doctoral education in nursing (63-74). Portland, OR: Oregon Health Sciences University School of Nursing.

Murphy, J.F. (1981). Doctoral education in, of, and for nursing: An historical analysis. Nursing Outlook, 29(11), 645-649.

Orem, D.E. (1991). Nursing: Concepts of practice (4th ed.). New York: McGraw-Hill.

Porter, C.P., \& Villarruel, A.M. (1993). Nursing research with African American and Hispanic people: Guidelines for action. Nursing Outlook, 41(2), 59-67.

Splane, V.H., \& Splane, R.B. (1994). International nursing leaders. In J. McCloskey \& H.K. Grace (Eds.). Current issues in nursing (4th ed.) (4956). St. Louis, MO: Mosby-Year Book.

US Department of Health and Human Services. (1990). Healthy people 2000: National health promotion and disease prevention objectives. Superintendent of documents. Washington, D.C.: US Government Printing Office.

Werley, H.H., \& Lang, N.M. (Eds.). (1988). Identification of the nursing minimum data set. New York: Springer.

Zwanger, L. (1987). International perspectives and implications for doctoral education in nursing: The Israeli case. In International perspectives and implications for doctoral education in nursing (17-43). Portland, Or: Oregon Health Sciences University School of Nursing. 